\title{
Extralobar pulmonary sequestration diagnosed intraoperatively in a 37 year-old male with bullous lung disease
}

\author{
Malek Tabbara*1, Fayez Abou Jaoude ${ }^{2}$ \\ ${ }^{1}$ Department of General and Digestive Surgery, Avicenne University Hospital, Paris XIII University, Paris, France \\ ${ }^{2}$ Department of Cardiovascular and Thoracic Surgery, Rafic Hariri University Hospital, Beirut, Lebanon
}

\author{
Received: June 25, 2015 \\ Accepted: July 17, 2015 \\ Online Published: August 8, 2015 \\ DOI: $10.5430 /$ css.v1n1p19 \\ URL: http://dx.doi.org/10.5430/css.v1n1p19
}

\begin{abstract}
Pulmonary sequestration is a rare congenital abnormality. It is characterized by a mass of non-functioning, embryonic, cystic pulmonary tissue that receives its blood supply from the systemic circulation. The presentation is variable, ranging from no symptoms to hemoptysis. Herein, we present a case of an asymptomatic pulmonary sequestration incidentally diagnosed intra-operatively in a 37 year-old male with diffuse bullous lung disease.
\end{abstract}

Key Words: Extralobar pulmonary sequestration, Congenital, Lobectomy

\section{INTRODUCTION}

Pulmonary sequestration is a rare congenital abnormality. It is characterized by a mass of non-functioning, embryonic, cystic pulmonary tissue that receives its blood supply from the systemic circulation. ${ }^{[1]}$ The presentation is variable, ranging from no symptoms to hemoptysis. Herein, we present a case of pulmonary sequestration incidentally diagnosed intra-operatively in a 37 year-old male with diffuse bullous lung disease.

\section{CASE PRESEntation}

This is a 37 year-old gentleman, with a smoking history of 18 packs/year, who was referred to our clinic for bilateral bullous lung disease. The patient had presented two months prior to our clinic visit to an outside hospital with shortness of breath and cough and was found to have left lung pneumonia for which he received oral antibiotic treatment. However his cough was persistent for more than 4 weeks, which prompted his doctor to order a repeat chest radiograph (see Figure 1) and a non-contrast computer tomography scan of the chest (see Figure 2). This latter showed diffuse bullous lung disease, predominantly on the left side. The largest bulla on the left side measured $15 \mathrm{~cm} \times 10 \mathrm{~cm}$ and had caused almost a complete collapse of the left lung. The patient was referred to us for bullectomy. The patient was seen and cleared for surgery by the anesthesia team. The patient was taken to the operating room and selective intubation was performed. A large left thoracotomy incision was made at the 5th intercostal space level and the wound was deepened to the ribs by cautery. The pleura was then opened carefully and the bullae identified. We were not able to free the bullae completely as it had adhered to the thoracic wall and was filling almost all the pleural space. We cut through the bullae to deflate it and identified that it originates from the left inferior lobe. The

*Correspondence: Malek Tabbara; Email: malektabbara@gmail.com; Address: 6 Ave René Fonck, 75019, Paris, France. 
bullae was stapled at its origin and removed. On inspection we identified multiple small bullae especially in the lower lobe compromising its function. On further exploration, we noticed that the basal segment of the lower lobe had a different texture and different color than the rest of the lung, with no sign of carbon particles deposits, thus not communicating with the rest of the lung. This was consistent with extralobar pulmonary sequestration (PS) with an afferent arterial branch from the thoracic aorta. It measured $10 \mathrm{~cm} \times 4 \mathrm{~cm} \times 2 \mathrm{~cm}$. Based on these findings (multiple bullae + PS) the decision to perform an inferior lobe resection was taken. The left inferior pulmonary artery, the left inferior pulmonary vein and the left inferior lobe main bronchus were identified and ligated. A Satinsky clamp was applied at the aortic origin of the feeding artery and the artery was cut $1 \mathrm{~cm}$ above the clamp. Then we proceeded by suturing the artery above the clamp. The lower lobe was then freed from its attachments and adhesions to the diaphragm and was removed and sent to pathology. Hemostasis was obtained. Two thoracostomy tubes were inserted in the thoracic cavity and the wound was closed. The patient tolerated the procedure without any complications and was transferred to the recovery room and then to a regular surgical floor.

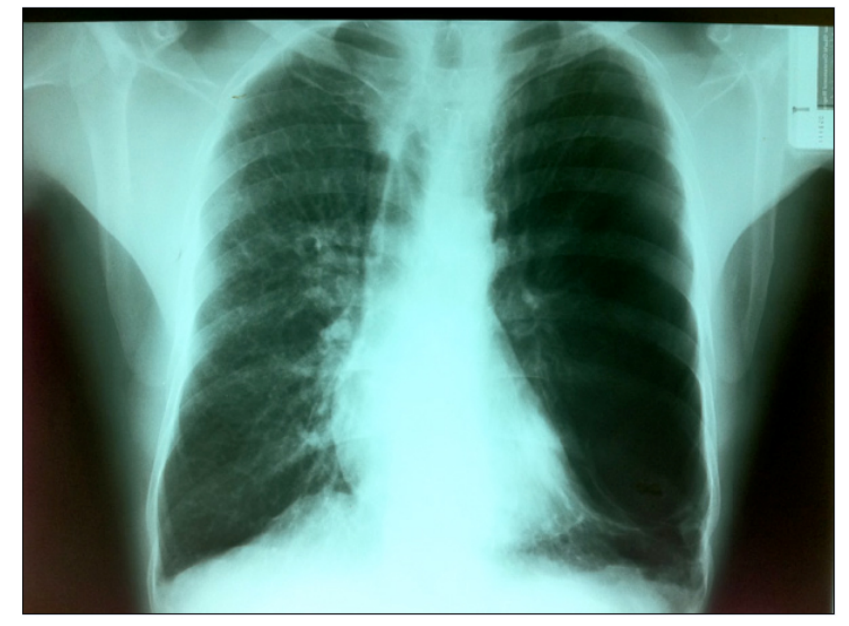

Figure 1. Chest radiograph on presentation to the outside clinic

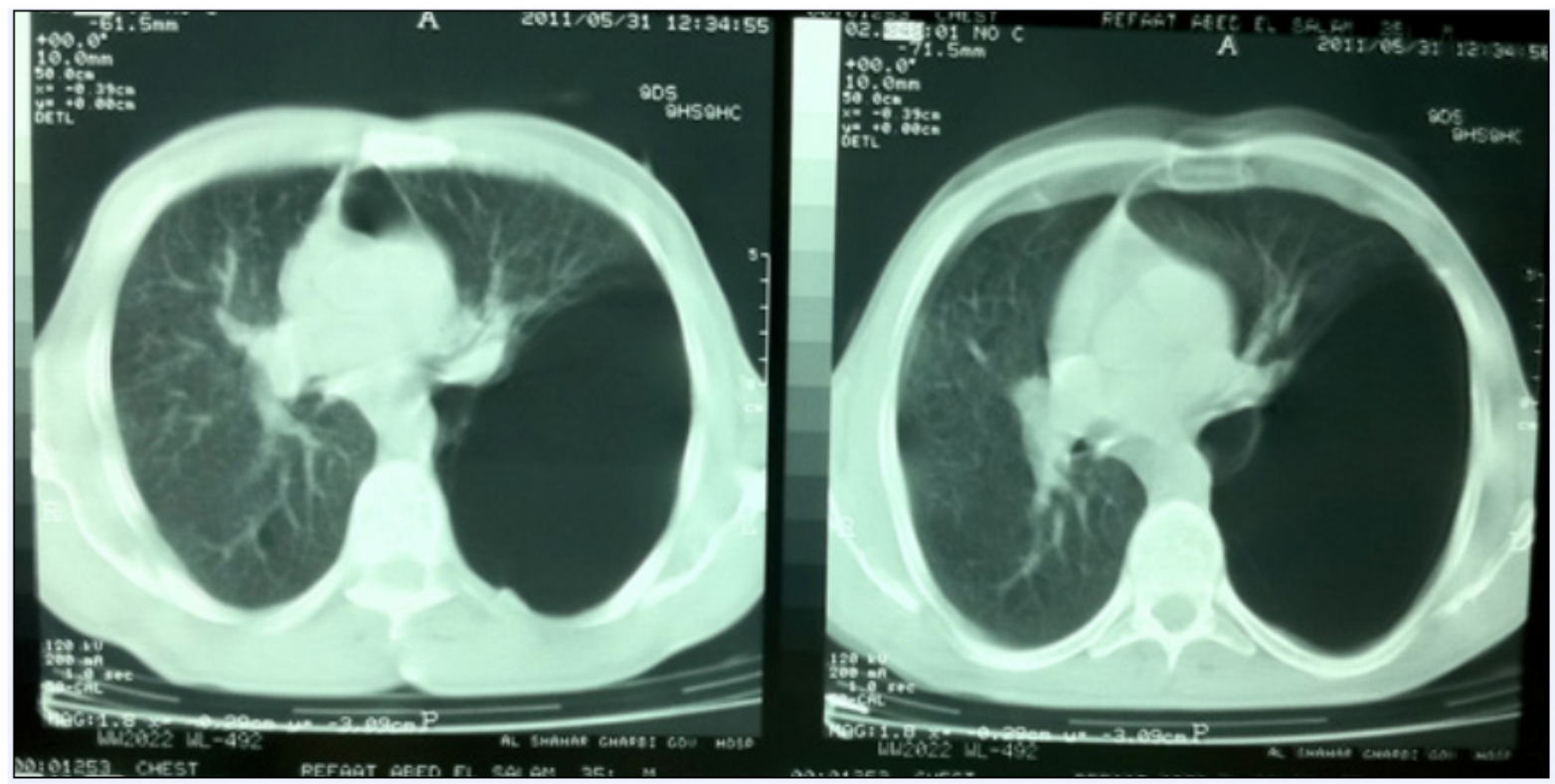

Figure 2. Chest CT scan after 4 weeks of chronic cough

On post-operative day one (POD-1) a chest plain radiograph was done and showed a full expansion of the left lung. The patient was able to ambulate on POD-1 and was encouraged to use the incentive spirometer on regular basis. Patient was discharged home in a stable condition on POD- 8 after his thoracostomy tubes were removed. The final pathology report described the segment with PS as lung parenchyma with intra-alveolar hemorrhage, fibrous thickening, and moderate intimal sclerosis with foamy macrophages.

\section{Discussion}

PS are rare congenital anomalies $-0.15 \%-6.4 \%$ of all congenital pulmonary malformations ${ }^{[2]}$ - where a segment of pulmonary tissue has no developmental connection to the tracheobronchial tree or pulmonary arterial circulation. PS are divided according to their relationship with the pleura into intralobar and extralobar types.

In intralobar sequestration (ILS), the isolated portion is anatomically part of a normal lobe and it lacks its own vis- 
ceral pleura. In extralobar sequestration (ELS), the isolated tissue is separated from the normal lung, and has its own visceral pleura as in our patient. ${ }^{[3]}$ The intralobar variety is much more common ( $75 \%$ of all PS). ELS has a male predominance $(80 \%)$ whereas ILS follows an equal gender distribution. ${ }^{[4]}$ The arterial supply of $75 \%$ of PS is usually from an aberrant vessel branch arising from the thoracic or abdominal aorta. In our case, it was the thoracic aorta. The remaining $25 \%$ of PS could receive their blood supply from subclavian, intercostal, pulmonary, pericardiophreinic, innominate, internal mammary, celiac, splenic or renal arteries. The venous drainage can be either to the pulmonary or to the systemic venous circulation. Intralobar sequestrations usually drain into pulmonary veins; extralobar sequestrations usually drain into the azygos system. ${ }^{[5]}$ ELS is more likely than ILS to be associated with anomalies, including congenital diaphragmatic hernia or eventration, cardiac defects, and foregut anomalies. ${ }^{[6]}$

Clinically, PS is usually latent until infection leads to symptoms. Recurrent pneumonitis of the sequestrated segment, purulent sputum and hemoptysis are the prevailing symptoms. ${ }^{\text {[7] }}$ Symptoms are usually absent in ELS since it is enveloped in its own pleural sac and it rarely gets infected. Many times, it is discovered incidentally on a chest radiograph taken for another reason. About two-thirds of all PS are found in the posterior segment of the left lower lobe. ${ }^{[8]}$

On radiograph, PS typically appears as a uniformly dense mass within the thoracic cavity or pulmonary parenchyma. The initial impression is usually one of pneumonia, though the lesion may appear as air- or fluid-filled cysts. In our case the diagnosis was missed on chest radiograph due to the large bulla occupying almost all the left pleural space. Till recently, arteriogram was considered the gold standard to diagnose sequestration and demonstrate its blood supply.

However the development of CT scanning and recently spiral CT angiography offer less invasive and very accurate (90\%) means of demonstrating the anomalous vascular supply. ${ }^{[9]}$ Again the diagnosis was missed on the CT scan in our case due to the suboptimal low quality and non-contrast images. In retrospect when reviewing the CT scan images (see Figure 2 ), there was a small structure which seems to arise from the left antero-lateral face of the aorta that could probably indicate the aberrant artery of the PS, however this was not very evident in the pre-operative reading. Surgical excision is usually recommended and curative; it should be conservative, sparing the normal lung parenchyma. ${ }^{[10]}$

PS in adults is difficult to diagnose before the operation, even with a detailed computer tomography examination. Hauer et al. ${ }^{[11]}$ published a series of 23 patients where the preoperative diagnosis was made only in 5 patients. Among the primary diagnosis for the remaining 18 patients they described 2 patients with emphysematous bullae. One patient was found to have right EL PS and underwent a sequestrectomy that was complicated post-operatively by respiratory insufficiency and the second patient had a right IL PS managed by lower lobectomy without any complications. The primary diagnosis of the other 16 patients ranged from lung cancer, lung abscess, lung cyst and bronchiectasis. Similar reports ${ }^{[12-14]}$ have been published describing PS cases presenting as or in coexistence with another lung disease (sarcoma, adenocarcinoma, mediastinal tumor). All of the abovementioned reports failed to discuss or prove any pathophysiologic relation between the PS and the coexistent lung disease.

\section{Conclusion}

To our knowledge this is the first case of extralobar PS that present as a bilateral diffuse bullous lung disease in an adult patient. PS could coexist with another lung disease in adult patients, which can result to a misleading and difficult preoperative diagnosis despite all the radiologic advancements. Vigilant per-operative inspection remains critical in making the final diagnosis, deciding the accurate treatment and avoiding any future complications.

\section{CONSENT}

Written informed consent was obtained from the patient for publication of this Case report and any accompanying images. A copy of the written consent is available for review by the Editor-in-Chief of this journal.

\section{CONFLicts of InTEREST Disclosure}

The authors declare that they have no competing interests.

\section{REFERENCES}

[1] Clements BS, Warner JO. Pulmonary sequestration and related congenital bronchopulmonary vascular malformations: nomenclature and classification based on anatomical and embryological considerations. Thorax. 1987; 42: 401-8. http://dx.doi.org/10.1136/t

Published by Sciedu Press $\mathrm{hx} \cdot 42.6 .401$

[2] Sade RM, Clouse M, Ellis FH. The spectrum of pulmonary sequestration. Ann Thorac Surg. 1974; 18: 644-58. http://dx.doi.org /10.1016/S0003-4975 (10)64417-7

[3] Skandalakis JE, Gray SW, Symbas P. Pulmonary circulation. In: 
Skandalakis JE, Gray SW, editors. Embryology for surgeons. Baltimore: Williams and Wilkins; 1994. 451-90p.

[4] Dyer JD, Anderson JM, John PR. A familial case of pulmonary arterial sequestration. Arch Dis Child. 2000; 82: 148-9. http: //dx.doi.org/10.1136/adc.82.2.148

[5] Franco J, Aliaga R, Domingo ML, et al. Diagnosis of pulmonary sequestration by spiral CT angiography. Thorax. 1998; 53: 1089-92. http://dx.doi.org/10.1136/thx.53.12.1089

[6] Vijayaraghavan SB, Rao PS, Selvarasu CD, et al. Prenatal sonographic features of intralobar bronchopulmonary sequestration. J Ultrasound Med. 2003; 22: 541-4. PMid: 12751868.

[7] Samuel M, Burge DM. Management of antenatally diagnosed pulmonary sequestration associated with cystic adenomatoid malformation. Thorax. 1999; 54: 701-6. http://dx.doi.org/10.1136/t $\mathrm{hx} .54 .8 .701$

[8] Halkic N, Cuenoud PF, Corthesy ME, et al. Pulmonary sequestration: a review of 26 cases. Eur J Cardiothorac Surg. 1999; 14: 127-33. http://dx.doi .org/10.1016/S1010-7940(98)00154-7

[9] Kang M, Khandelwal N, Ojili V, et al. Multidetector CT angiography in pulmonary sequestration. J Comput Assist Tomogr. 2006; 30:
926-32. PMid: 17082698. http://dx.doi.org/10.1097/01.rc t. 0000224626.94703 .61

[10] Bonnard A, Malbezin S, Ferkdadji L, et al. Pulmonary sequestration children: is the thoracoscopic approach a good option? Surg Endosc. 2004; 18: 1364-7. PMid: 15803237. http://dx.doi.org/10.10 07/s00464-003-9247-x

[11] Hauer J, Alchimowicz J, Harazda M, et al. Pulmonary Sequestration - Analysis of Diagnostic and Therapeutic Difficulties. Polish Journal of Surgery [Internet]. De Gruyter Open Sp. z o.o.; 2007 Jan 1; 79(1) http://dx.doi.org/10.2478/v10035-007-0005-y

[12] Di Crescenzo V, Laperuta P, Napolitano F, et al. Pulmonary sequestration presented as massive left hemothorax and associated with primary lung sarcoma. BMC Surg. 2013; 13 Suppl 2: S34. http: //dx.doi.org/10.1186/1471-2482-13-S2-S34

[13] Belchis D, Cowan M, Mortman K, et al. Adenocarcinoma arising in an extralobar sequestration: a case report and review of the literature. Lung Cancer. 2014 Apr; 84(1): 92-5. http://dx. doi .org/10.10 16/j.lungcan.2014.01.025

[14] Ke FJ, Chang SC, Su WJ, et al. Extralobar pulmonary sequestration presenting as an anterior mediastinal tumor in an adult. Chest. 1993 Jul; 104(1): 303-4. PMid: 8325097. http://dx.doi .org/10.13 $78 /$ chest. 104.1 .303 